\title{
Foetal Gender and Obstetric Outcome
}

\section{Fetales Geschlecht und geburtshilfliches Outcome}

Authors

Affiliations
B. Schildberger ${ }^{1}$, H. Leitner ${ }^{2}$

${ }^{1}$ FH Gesundheitsberufe OÖ, Linz, Österreich

${ }^{2}$ Institut für klinische Epidemiologie der Tirol Kliniken, Innsbruck, Österreich
Deutsche Version unter: www.thieme-connect.de/ ejournals/gebfra

\section{received $\quad 8.7 .2015$ \\ revised $\quad 8.11 .2015$ \\ accepted 9.11.2015}

\section{Bibliography}

Dol http://dx.doi.org/

10.1055/s-0041-109198

Geburtsh Frauenheilk 2016; 76:

255-260 @ Georg Thieme

Verlag KG Stuttgart · New York .

ISSN 0016-5751

\section{Correspondence}

\section{Barbara Schildberge}

University of Applied Science

for Health Professions

Upper Austria

Campus Health, Landes-

Frauen- und Kinderklinik

Bachelor Programme Midwifery

Krankenhausstraße 26-30

4020 Linz

Austria

Barbara.schildberger@

fhgooe.ac.at

\section{Abstract \\ $\nabla$}

Introduction: Data on specific characteristics based on the gender of the unborn baby and their significance for obstetrics are limited. The aim of this study is to analyse selected parameters of obstetric relevance in the phases pregnancy, birth and postpartum period in dependence on the gender of the foetus.

Materials and Methods: The selected study method comprised a retrospective data acquisition and evaluation from the Austrian birth register of the Department of Clinical Epidemiology of Tyrolean State Hospitals. For the analysis all inpatient singleton deliveries in Austria during the period from 2008 to 2013 were taken into account (live and stillbirths $n=444685$ ). The gender of the baby was correlated with previously defined, obstetrically relevant parameters.

Results: In proportions, significantly more premature births and sub partu medical interventions (vaginal and abdominal surgical deliveries. episiotomies) were observed for male foetuses $(\mathrm{p}<0.001)$. The neonatal outcome (5-min Apgar score, umbilical $\mathrm{pH}$ value less than 7.1 , transfer to a neonatal special unit) is significantly poorer for boys ( $\mathrm{p}<0.001)$.

Discussion: In view of the vulnerability of male foetuses and infants, further research is needed in order to be able to react appropriately to the differing gender-specific requirements in obstetrics.

\section{Introduction \\ $\nabla$}

The available studies on foetal gender as a specific influencing variable during pregnancy and birth are limited. In comparison our knowledge on the progress of infantile growth is relatively certain. In 280 days the unborn baby achieves a length of

\section{Zusammenfassung \\ $\nabla$}

Einleitung: Die Studienlage über die vom Geschlecht des ungeborenen Kindes ausgehenden Spezifika und deren Bedeutung in der Geburtshilfe ist limitiert. Ziel der Arbeit ist, anhand ausgewählter, geburtshilflich relevanter Parameter die Phasen Schwangerschaft, Geburt und Wochenbett in Abhängigkeit zum fetalen Geschlecht zu analysieren.

Material und Methoden: Als Methode wurde eine retrospektive Datenerhebung und -auswertung aus dem Geburtenregister Österreich des Instituts für klinische Epidemiologie der Tirol Kliniken gewählt. Zur Analyse wurden alle stationären Einlingsgeburten in Österreich im Zeitraum von 2008-2013 (Lebend- und Totgeburten $\mathrm{n}=444685$ ) herangezogen. Das Geschlecht des Kindes wurde mit vorab definierten, geburtshilflich relevanten Variablen in Beziehung gesetzt. Ergebnisse: Im Verhältnis sind bei männlichen Feten signifikant mehr Frühgeburten und medizinische Interventionen sub partu (vaginal und abdominal operativer Entbindungsmodus, Episiotomie) zu verzeichnen $(p<0,001)$. Das neonatale Outcome (5-min-Apgar-Wert, Na-pH-Wert unter 7,1 , Verlegung auf neonatologische Abteilung) ist bei Knaben signifikant schlechter $(p<0,001)$.

Diskussion: Im Hinblick auf die Vulnerabilität von männlichen Feten und Neugeborenen ist weitere Forschung notwendig, um in der Geburtshilfe den geschlechtsspezifisch unterschiedlichen Bedarfen entsprechend agieren zu können.

ca. 50 centimetres, whereby infant boys have on average a body length 1 centimetre and a head circumference of ca. 5 millimetres more than infant girls. At all times during pregnancy female foetuses have larger length-weight and head circumference-weight ratios than males. Already in the second trimester girls exhibit a shorter femur 
length and a smaller biparietal head diameter. Although girls show a lower intrauterine growth in comparison to boys they exhibit an accelerated maturation of about 4-6 weeks [1].

Various studies have shown that placental dysfunctions, especially severe pre-eclampsia and intrauterine growth retardation, occur significantly more frequently in pregnancies involving a male foetus. The placentas of male foetuses exhibit significantly higher rates of deciduitis and velamentous navel insertions as well as a significantly lower incidence of placental infarction than the placenta of female foetuses [2-6].

In the mothers of male infants, in comparison to the mothers of female babies, higher incidences of premature rupture of membranes and premature births can be observed [7]. The rates of gestational diabetes mellitus, macrosomia, protracted opening and expulsion phases, umbilical cord prolapses, umbilical cord looping and genuine umbilical cord knots are significantly elevated. Furthermore, male babies are more frequently delivered by Caesarean section than female babies [7-9].

Also, the rates of vaginal surgical deliveries are higher, and the indication for birth completion is more frequently given with the diagnosis of "threatening intrauterine asphyxia" in the case of male babies. The rate of sonographically diagnosed growth retardation, however, is higher for female infants [10].

Several studies have recognised male gender as being a risk factor during pregnancy and birth. The biological mechanisms of this gender-specific difference are, however, still virtually unknown even though various theories discuss the influence of hormonal, physiological or genetic factors $[8,11-14]$.

Although new management strategies have led to better and better therapeutic results for very preterm infants, boys still exhibit higher mortality and morbidity than girls. For boys in the group of very preterm infants significant differences can be seen in the criteria higher birth weight, oxygen dependency, hospital stay, pulmonary bleeding, treatment with steroids, skull anomalies and mortality. These differences also remain significant in the subsequent course. The authors conclude that male gender per se represents a risk factor for the poor general condition of very premature babies as well as for their poorer developmental course [15-17].

The accelerated maturation for girls is well known and, in the neonatal period and infancy, results in girls having a markedly greater ability to form a primary relationship, being emotional stable, easier to calm down and being less restless. The perception of social and other interactions starts earlier in girls. In boys, on the other hand, the early ability to form relationships and coping strategies, for example, in cases of pain and discomfort are influenced by the greater restlessness, the delayed development of sleep rhythm and the vulnerability. "In unfavourable circumstances this leads to a higher degree of psychophysical stress in the male child" [18].

The consideration of gender-specific components already in the perinatal phase should, in the sense of the aims of gender medicine, help to optimise the preventative, diagnostic, therapeutic and rehabilitation processes of general and health care from the very beginning "to act as an important step and bridge towards personalised medicine" [19].

The aim of this study is to consider with the help of selected obstetrically relevant parameters the phases pregnancy, birth and postpartum period in relation to foetal gender. On the basis of the above-mentioned considerations, we posed the following guiding question for our research: what influence does foetal gender have on selected obstetric parameters?

\section{Materials and Methods}

$\nabla$

For this publication we have obtained a positive vote from the Ethics Commission of Upper Austria and permission for the data analysis from the board of the Austrian birth register at the Department of Clinical Epidemiology of Tyrolean State Hospitals in Innsbruck.

We have decided upon a retrospective data acquisition and evaluation from the Austrian birth register as method for this study. The Austrian birth register contains the results of all births occurring in hospitals in Austria since 2008 in an epidemiological data base.

\section{Samples and variables}

For the analysis, all inpatient singleton births in Austria in the period from 2008 to 2013 ( $n=444685$ live births) were included. The gender of the baby was correlated with the following, previously defined and obstetrically relevant variables: parity, duration of pregnancy, birth weight, tocolysis, position of the baby at birth, drug-induced labour, micro blood gas analysis sub partu, peridural or spinal anaesthesia, delivery mode, delivery position, duration of delivery, performance of episiotomy, perineal trauma, 5-min Apgar score, umbilical cord $\mathrm{pH}$, disorder of placenta separation, transfer of the infant post partum to neonatal department, perinatal mortality.

The parameters duration of delivery, episiotomy, 5-min Apgar score, umbilical cord $\mathrm{pH}$ under 7.1 and transfer of the baby to a neonatal department were additionally analysed with the specific sample "live birth at term" (gestational weeks 36+6-42+0) $(n=411380)$, in order to enable a differentiated presentation of the results.

\section{Statistical evaluation}

The $\mathrm{X} 2$ test was used for the statistical evaluation and presentation of the results. As a consequence of the large sample size statistically significant results are possible already for small differences and have to be considered for their clinical relevance.

\section{Results}

$\nabla$

Among the total number of all inpatient live births from singleton pregnancies in Austria in the period 2008-2013 $(n=444685)$ $51.5 \%$ were boys and $48.5 \%$ were girls ( Table 1 ).

On analysis of the parity and its relationship to the gender of the baby, at first, no significant differences can be determined. Only after the mother's 7th delivery does a difference become visible: the relationship for boys of $56 \%$ is significantly higher than that for girls with $44 \%$.

\section{Duration of pregnancy and birth weight}

The proportion of male infants is markedly higher than that for female infants not only for the extremely preterm births (weeks of gestation $<27+6$ ) and the very preterm births (weeks of gestation $28+0-31+6$ ) but also for the late preterm births (weeks of gestation 32+0-36+6) (55.1:44.9\%; 56.3:43.8\%; 55.2:44.8\%). For term births, the ratio of girls to boys is balanced. Significantly more boys ( $53.4 \%$ ) than girls ( $46.6 \%$ ) are born after completion of the 42nd week of pregnancy ( $\mathrm{p}<0.001)$.

For the birth weights of the babies, it is seen that in the category under $500 \mathrm{~g}$ the ratio of male infants with $47.1 \%$ is markedly lower than that of female infants with $52.9 \%$. In the category be- 
tween $500 \mathrm{~g}$ and $750 \mathrm{~g}$ the ratio of boys to girls is balanced. The ratio of male to female infants is significantly higher in the categories $750-999 \mathrm{~g}$ (55.3\% boys and $44.7 \%$ girls) and $1000-1499 \mathrm{~g}$ (52.6\% boys and $47.4 \%$ girls) ( $\mathrm{p}<0.001)$. In the category $1500-$ $2499 \mathrm{~g}$ the ratio is reversed ( $46.5 \%$ boys and $53.5 \%$ girls), in the category $2500-3999 \mathrm{~g}$ it is balanced and in the category $4000-$ $6500 \mathrm{~g}$ again markedly elevated in favour of boys (66.4\% boys and $33.6 \%$ girls).

The proportion of pregnancies and births in which tocolysis was applied is markedly higher for male foetuses with $55.4 \%$ as compared to females with $44.6 \%$.

\section{Sub partu interventions and delivery mode}

For the parameters position of the baby at delivery, the ratio of boys to girls is relatively balanced for the proper cephalic position. On the other hand, there are marked differences with higher proportions for boys in cases with anomalous cephalic presentation ( $52.7 \%$ boys, $47.3 \%$ girls) and transverse presentation ( $53.8 \%$ boys, $46.2 \%$ girls) and there are significantly more girls with breech presentations at birth (45.6\% boys, $54.4 \%$ girls) $(\mathrm{p}<0.001)$.

With regard to drug-induced labour and foetal gender no differences could be found.

Micro blood gas analyses during birth for evaluation of the general condition of the infant were employed significantly more often for boys (55\%) than for girls $(45 \%)(\mathrm{p}<0.001)$.

Use of peridural or, respectively, spinal anaesthesia as pain therapy during birth was requested similarly independent of the gender of the unborn baby.

With regard to the mode of delivery, there were no significant differences between the genders of the babies in the categories "spontaneous birth" and "primary Caesarean section". The proportion of boys is markedly higher than that of girls in the vaginal surgical delivery modes (vacuum: $56.8 \%$ boys, $43.2 \%$ girls; forceps: $62.4 \%$ boys, $37.6 \%$ girls) and also in the category "secondary Caesarean section" ( $55.7 \%$ boys, $44.3 \%$ girls).

For the parameter position of the baby in vaginal deliveries, the Austrian birth register records the categories "delivery room bed", "stool delivery", "water birth" and "others". In the context of these categories no relevant differences between the foetal genders could be demonstrated.

For the duration of delivery, no relationships with foetal gender could be derived. In the case of duration of delivery in excess of 24 hours, the proportion of girls is slightly elevated as compared to boys, and this is also the case in the sample of term births.

With 54.6\%, episiotomies are performed significantly more frequently in the births of boys than in the births of girls $(p<0.001)$. If we consider only the sample of term births (weeks of gestation $36+6$ to $42+0$ ), the result is very similar. In this subgroup the ratio is $54.4 \%$ for the boys and $45.6 \%$ for the girls.

Similarly, perineal traumata, especially severe perineal traumata are more frequent in the course of birth of boys than during the birth of girls.

Disorders of placental separation are significantly less frequent with $47.2 \%$ in the placentas of male foetuses than in the placentas of female foetuses with $52.8 \%$.

\section{Perinatal outcome}

In the case of the 5-min Apgar score as instrument to evaluate the clinically identifiable general condition of the new born baby we find a significantly higher proportion especially of low scores for the boys. For all new born infants exhibiting an Apgar score of 910 after 5 minutes, the ratio between boys and girls is balanced. This tendency can also be seen when the reduced sample of live births at term is used in the analysis (weeks of gestation $36+6-$ $42+0)$.

The proportion of boys with an umbilical cord $\mathrm{pH}$ value of less than 7.1 is $53.9 \%$ which is significantly higher than that for the girls with $46.1 \%$. Also in the sample of live births at term, boys show a significantly higher proportion of $53.6 \%$ than girls with $46.4 \%(\mathrm{p}<0.001)$.

Transfer of the new born baby to a neonatal department between birth and the 7th day after birth in all categories is significantly more frequently necessary for boys than for girls. The same result is found on evaluating the sample of live births at term.

The obstetric parameter mortality prior to birth $(n=2214)$ does not exhibit any differences with regard to the gender of the foetus. During delivery the relative proportion of male foetuses with $63.3 \%$ as compared to $36.7 \%$ for the female foetuses is markedly elevated as it is also after birth with $63.3 \%$ for the boys and $36.7 \%$ for the girls.

\section{Discussion \\ $\nabla$}

An analysis of selected, obstetrically relevant parameters in relation to the gender of the foetus provides a contribution to the gender-oriented optimisation of general and health-care management. Our results are, in principle, in accord with the results of studies by Di Renzo et al. (2007), Aibar et al. (2012) and Khalil (2013) and demonstrate that male foetuses have a higher vulnerability in the perinatal phase and a high obstetric risk $[7,10,11]$. The high tendency towards premature births or, respectively, the higher rate of preterm births for boys revealed by these data confirms the results of previous studies [2,3,6,7]. Di Renzo et al. assumed that the higher incidences of premature rupture of membranes and preterm births among boys can be attributed to their relatively higher weights and lower gestational ages [7]. However, this assumption contradicts the results of Challis et al. (2013), who demonstrated in their study that chorionic trophoblast cells from pregnancies with a male foetus possess the potential to generate a pro-inflammatory environment by which the significantly higher rate of male preterm births than female preterm births can be explained [20]. This further substantiates the results of Zeitlin et al. (2004) that the tendency for preterm births among boys is significantly more frequently due to the spontaneous onset of contractions and less often due to a medically indicated and drug-induced completion of the pregnancy [21]. This generally high rate of preterm births requires more research initiatives on the pathophysiological processes. For this there is a need to acquire basic knowledge about the intrinsic and extrinsic triggers of the threatening preterm birth as a complex event under consideration of gender-specific characteristics.

We can also confirm the high rates of interventions among males foetuses sub partu (vaginal surgical conclusion of the birth process, Caesarean section) demonstrated in the studies of Di Renzo et al., Sheiner et al. and Dunn et al. [7,8,14]. The relatively higher rate of micro blood gas analyses (MBA) employed during the birth of boys allows the conclusion of a higher rate of at least suspected hypoxia in the foetal metabolism. In this context it is still not clear whether the physiological characteristics of boys lead more often to stress phases during birth or if the interpretation of findings (above all of CTG and MBA) require a gender-specific differentia- 
Table 1 Representation of the proportions of boys and girls arranged according to the obstetric parameters. The influence of the foetal gender on selected obstetric parameters.

\begin{tabular}{|c|c|c|c|}
\hline \multirow[t]{2}{*}{ Obstetric parameter } & \multicolumn{3}{|c|}{ Gender of the infant } \\
\hline & male & female & total \\
\hline \multicolumn{4}{|l|}{ Live births } \\
\hline > singleton & $229014(51.5 \%)$ & $215671(48.5 \%)$ & $444685(100.0 \%)$ \\
\hline \multicolumn{4}{|l|}{ Parity } \\
\hline$>0$ & $112365(51.6 \%)$ & $105603(48.4 \%)$ & $217968(100.0 \%)$ \\
\hline$>1$ & $78316(51.4 \%)$ & $73994(48.6 \%)$ & $152310(100.0 \%)$ \\
\hline$>2$ & $26793(51.4 \%)$ & $25300(48.6 \%)$ & $52093(100.0 \%)$ \\
\hline$>3$ & $7766(51.7 \%)$ & $7255(48.3 \%)$ & $15021(100.0 \%)$ \\
\hline$>4$ & $2422(51.8 \%)$ & $2253(48.2 \%)$ & $4675(100.0 \%)$ \\
\hline$>5$ & $786(50.1 \%)$ & $782(49.9 \%)$ & $1568(100.0 \%)$ \\
\hline$>6$ & $311(56.0 \%)$ & $244(44.0 \%)$ & $555(100.0 \%)$ \\
\hline \multicolumn{4}{|c|}{ Pearson $X^{2}(6)=6.8979 \mathrm{Pr}=0.330$} \\
\hline \multicolumn{4}{|c|}{ Duration of pregnancy - weeks of gestation } \\
\hline > $15+0-27+6$ & $789(55.1 \%)$ & $644(44.9 \%)$ & $1433(100.0 \%)$ \\
\hline > $28+0-31+6$ & $1413(56.3 \%)$ & $1099(43.8 \%)$ & $2512(100.0 \%)$ \\
\hline$-32+0-36+6$ & $13766(55.2 \%)$ & $11153(44.8 \%)$ & $24919(100.0 \%)$ \\
\hline - $37+0-41+6$ & $210710(51.2 \%)$ & $200670(48.8 \%)$ & $411380(100.0 \%)$ \\
\hline$>\geq 42+0$ & $1546(53.4 \%)$ & $1347(46.6 \%)$ & $2893(100.0 \%)$ \\
\hline \multicolumn{4}{|l|}{ Pearson $X^{2}(4)=186.9733 \operatorname{Pr}=0.000$} \\
\hline \multicolumn{4}{|l|}{ Birth weight } \\
\hline$><500 \mathrm{~g}$ & $120(47.1 \%)$ & $135(52.9 \%)$ & $255(100.0 \%)$ \\
\hline > 500-749 & $281(50.5 \%)$ & $275(49.5 \%)$ & $556(100.0 \%)$ \\
\hline - 750-999 & $394(55.3 \%)$ & $318(44.7 \%)$ & $712(100.0 \%)$ \\
\hline > $1000-1499$ & $999(52.6 \%)$ & $900(47.4 \%)$ & $1899(100.0 \%)$ \\
\hline - 1500-2499 & $8789(46.5 \%)$ & $10098(53.5 \%)$ & $18887(100.0 \%)$ \\
\hline - 2500-3999 & $192315(50.2 \%)$ & $190619(49.8 \%)$ & $382934(100.0 \%)$ \\
\hline > $4000-6500$ & $25822(66.4 \%)$ & $13084(33.6 \%)$ & $38906(100.0 \%)$ \\
\hline \multicolumn{4}{|l|}{ Pearson $x^{2}(6)=3.9 e+03 \operatorname{Pr}=0,000$} \\
\hline \multicolumn{4}{|l|}{ Intravenous tocolysis for the mother } \\
\hline > yes & $2550(55.4 \%)$ & $2051(44.6 \%)$ & $4601(100.0 \%)$ \\
\hline \multicolumn{4}{|l|}{ Pearson $x^{2}(1)=38.5233 \mathrm{Pr}=0.000$} \\
\hline \multicolumn{4}{|l|}{ Position of baby at birth } \\
\hline - appropriate cephalic presentation & $205194(51.7 \%)$ & $191581(48.3 \%)$ & $396775(100.0 \%)$ \\
\hline - anomalous cephalic presentation & $12697(52.7 \%)$ & $11383(47.3 \%)$ & $24080(100.0 \%)$ \\
\hline - breech presentation & $9389(45.6 \%)$ & $11194(54.4 \%)$ & $20583(100.0 \%)$ \\
\hline transverse presentation & $701(53.8 \%)$ & $603(46.2 \%)$ & $1304(100.0 \%)$ \\
\hline \multicolumn{4}{|l|}{ Pearson $x^{2}(3)=309.9401 \operatorname{Pr}=0.000$} \\
\hline \multicolumn{4}{|l|}{ Drug-induced labour } \\
\hline - yes & $27051(50.7 \%)$ & $26269(49.3 \%)$ & $53320(100.0 \%)$ \\
\hline \multicolumn{4}{|l|}{ Pearson $x^{2}(1)=0.5884 \mathrm{Pr}=0.443$} \\
\hline \multicolumn{4}{|l|}{ Micro blood gas analysis of infant } \\
\hline yes & $3638(55.0 \%)$ & $2972(45.0 \%)$ & $6610(100.0 \%)$ \\
\hline \multicolumn{4}{|l|}{ Pearson $x^{2}(1)=47.4789 \mathrm{Pr}=0.000$} \\
\hline PDA/spinal anaesthesia sub partu & & & \\
\hline yes & $51735(52.9 \%)$ & $45981(47.1 \%)$ & $97716(100.0 \%)$ \\
\hline Pearson $x^{2}(1)=14.6536 \mathrm{Pr}=0.000$ & & & \\
\hline Delivery mode & & & \\
\hline - spontaneous & $147106(50.3 \%)$ & $145490(49.7 \%)$ & $292596(100.0 \%)$ \\
\hline v vacuum & $16076(56.8 \%)$ & $12215(43.2 \%)$ & $28291(100.0 \%)$ \\
\hline - forceps & $352(62.4 \%)$ & $212(37.6 \%)$ & $564(100.0 \%)$ \\
\hline - breech/manual expulsion & $283(38.2 \%)$ & $457(61.8 \%)$ & $740(100.0 \%)$ \\
\hline - abdominal version & $2(40.0 \%)$ & $3(60.0 \%)$ & $5(100.0 \%)$ \\
\hline primary Caesarean section & $31382(50.8 \%)$ & $30387(49.2 \%)$ & $61769(100.0 \%)$ \\
\hline - secondary Caesarean section & $33456(55.7 \%)$ & $26614(44.3 \%)$ & $60070(100.0 \%)$ \\
\hline Pearson $x^{2}(6)=1.0 \mathrm{e}+03 \mathrm{Pr}=0.000$ & & & \\
\hline Delivery position & & & \\
\hline - delivery room bed & $140636(51.1 \%)$ & $134551(48.9 \%)$ & $275187(100.0 \%)$ \\
\hline > stool & $6772(50.1 \%)$ & $6747(49.9 \%)$ & $13519(100.0 \%)$ \\
\hline - water birth & $5827(48.6 \%)$ & $6153(51.4 \%)$ & $11980(100.0 \%)$ \\
\hline others & $6454(49.0 \%)$ & $6729(51.0 \%)$ & $13183(100.0 \%)$ \\
\hline
\end{tabular}


Table 1 Representation of the proportions of boys and girls arranged according to the obstetric parameters. The influence of the foetal gender on selected obstetric parameters. (Continued)

\begin{tabular}{|c|c|c|c|}
\hline \multirow[t]{2}{*}{ Obstetric parameter } & \multicolumn{3}{|c|}{ Gender of the infant } \\
\hline & male & female & total \\
\hline \multicolumn{4}{|c|}{ Duration of birth (start of contractions to delivery) } \\
\hline up to $12 \mathrm{~h}$ & $142783(50.8 \%)$ & $138441(49.2 \%)$ & $281224(100.0 \%)$ \\
\hline > $13-24 \mathrm{~h}$ & $12689(51.9 \%)$ & $11748(48.1 \%)$ & $24437(100.0 \%)$ \\
\hline more than $24 \mathrm{~h}$ & $1055(49.5 \%)$ & $1078(50.5 \%)$ & $2133(100.0 \%)$ \\
\hline \multicolumn{4}{|l|}{ Pearson $X^{2}(2)=13.6362 \operatorname{Pr}=0.001$} \\
\hline \multicolumn{4}{|l|}{ Duration of birth (only term births) } \\
\hline up to $12 \mathrm{~h}$ & $134109(50.5 \%)$ & $131658(49.5 \%)$ & $265767(100.0 \%)$ \\
\hline - $13-24 \mathrm{~h}$ & $12181(51.7 \%)$ & $11372(48.3 \%)$ & $23553(100.0 \%)$ \\
\hline more than $24 \mathrm{~h}$ & $983(48,8 \%)$ & $1033(51,2 \%)$ & $2016(100,0 \%)$ \\
\hline \multicolumn{4}{|l|}{ Pearson $x^{2}(2)=16.2652 \mathrm{Pr}=0.000$} \\
\hline \multicolumn{4}{|l|}{ Episiotomy } \\
\hline episiotomy & $33037(54.6 \%)$ & $27447(45.4 \%)$ & $60484(100.0 \%)$ \\
\hline \multicolumn{4}{|l|}{ Pearson $x^{2}(1)=421.8449 \mathrm{Pr}=0.000$} \\
\hline - episiotomy (only term births) & $31128(54.4 \%)$ & $26050(45.6 \%)$ & $57178(100.0 \%)$ \\
\hline \multicolumn{4}{|l|}{ Pearson $x^{2}(1)=423.8031 \mathrm{Pr}=0.000$} \\
\hline \multicolumn{4}{|l|}{ Perineal tears } \\
\hline - no perineal tear & $110497(50.5 \%)$ & $108510(49.5 \%)$ & $219007(100.0 \%)$ \\
\hline - PTI & $30344(50.3 \%)$ & $30000(49.7 \%)$ & $60344(100.0 \%)$ \\
\hline > PTII & $20081(53.0 \%)$ & $17780(47.0 \%)$ & $37861(100.0 \%)$ \\
\hline > PTIII & $2764(58.3 \%)$ & $1976(41.7 \%)$ & $4740(100.0 \%)$ \\
\hline > PTIV & $133(54.5 \%)$ & $111(45.5 \%)$ & $244(100.0 \%)$ \\
\hline \multicolumn{4}{|l|}{ Pearson $x^{2}(4)=200.9563 \operatorname{Pr}=0.000$} \\
\hline \multicolumn{4}{|l|}{ Placental separation disorder } \\
\hline yes & $5719(47.2 \%)$ & $6387(52.8 \%)$ & $12106(100.0 \%)$ \\
\hline \multicolumn{4}{|l|}{ Pearson $x^{2}(2)=65.6443 \operatorname{Pr}=0.000$} \\
\hline \multicolumn{4}{|l|}{ Apgar score after 5 minutes } \\
\hline $0-2$ & $498(54.1 \%)$ & $422(45.9 \%)$ & $920(100.0 \%)$ \\
\hline - 3-4 & $272(56.5 \%)$ & $209(43.5 \%)$ & $481(100.0 \%)$ \\
\hline > $5-6$ & $1311(59.6 \%)$ & $889(40.4 \%)$ & $2200(100.0 \%)$ \\
\hline - $7-8$ & $9212(56.8 \%)$ & $7018(43.2 \%)$ & $16230(100.0 \%)$ \\
\hline > $9-10$ & $216767(51.2 \%)$ & $206247(48.8 \%)$ & $423014(100.0 \%)$ \\
\hline \multicolumn{4}{|l|}{ Pearson $x^{2}(4)=255.9797 \mathrm{Pr}=0.000$} \\
\hline \multicolumn{4}{|l|}{ Apgar score after 5 minutes (only term births) } \\
\hline $0-2$ & $253(52.0 \%)$ & $234(48.0 \%)$ & $487(100.0 \%)$ \\
\hline$>3-4$ & $162(54.0 \%)$ & $138(46.0 \%)$ & $300(100.0 \%)$ \\
\hline - $5-6$ & $870(61.4 \%)$ & $548(38.6 \%)$ & $1418(100.0 \%)$ \\
\hline - $7-8$ & $6633(56.6 \%)$ & $5082(43.4 \%)$ & $11715(100.0 \%)$ \\
\hline > $9-10$ & $202051(51.0 \%)$ & $193949(49.0 \%)$ & $396000(100.0 \%)$ \\
\hline \multicolumn{4}{|l|}{ Pearson $X^{2}(4)=202.1802 \operatorname{Pr}=0.000$} \\
\hline umbilical pH below 7.1 & & & \\
\hline - umbilical pH below 7.1 (all live births) & $4865(53.9 \%)$ & $4154(46.1 \%)$ & $9019(100.0 \%)$ \\
\hline Pearson $x^{2}(1)=20.5651 \mathrm{Pr}=0.000$ & & & \\
\hline - umbilical pH below 7.1 (only term births) & $4458(53.6 \%)$ & $3863(46.4 \%)$ & $8321(100.0 \%)$ \\
\hline Pearson $x^{2}(1)=17.7195 \operatorname{Pr}=0.000$ & & & \\
\hline Infant transferred & & & \\
\hline up to 1 st calendar day after birth & $7888(57.5 \%)$ & $5829(42.5 \%)$ & $13717(100.0 \%)$ \\
\hline 2nd to 7th calendar day after birth & $4500(56.5 \%)$ & $3459(43.5 \%)$ & $7959(100.0 \%)$ \\
\hline - after 7th calendar day after birth & $1071(57.0 \%)$ & $807(43.0 \%)$ & $1878(100.0 \%)$ \\
\hline Pearson $x^{2}(3)=322.8287 \mathrm{Pr}=0.000$ & & & \\
\hline Infant transferred (only term births) & & & \\
\hline up to 1 st calendar day after birth & $4296(57.8 \%)$ & $3141(42.2 \%)$ & $7437(100.0 \%)$ \\
\hline 2nd to 7th calendar day after birth & $3740(56.4 \%)$ & $2886(43.6 \%)$ & $6626(100.0 \%)$ \\
\hline after 7th calendar day after birth & $474(58.6 \%)$ & $335(41.4 \%)$ & $809(100.0 \%)$ \\
\hline Pearson $x^{2}(3)=227.7274 \operatorname{Pr}=0.000$ & & & \\
\hline Mortality & & & \\
\hline - ante partum & $730(51.0 \%)$ & $702(49.0 \%)$ & $1432(100.0 \%)$ \\
\hline sub partu & $81(63.3 \%)$ & $47(36.7 \%)$ & $128(100.0 \%)$ \\
\hline post partum (day $1-7$ ) & $371(56.7 \%)$ & $283(43.3 \%)$ & $654(100.0 \%)$ \\
\hline Pearson $\chi^{2}(3)=14.4344 \mathrm{Pr}=0.002$ & & & \\
\hline
\end{tabular}


tion. In order to more exactly evaluate the foetal condition sub partu, we need a further specialisation of the possible monitoring and diagnostic options as well as their adaptation to gender-specific peculiarities.

The higher birth weight of boys may be a factor to help explain the higher rates of vaginal surgical deliveries and Caesarean sections. However, it has not been possible to confirm a relationship between higher birth weight and longer duration of birth. At duration of birth in excess of 24 hours the proportion of girls is even higher than that of boys.

As can be seen from the parameters 5-min Apgar score, umbilical $\mathrm{pH}$ value and transfer of the infant post partum, the higher intervention rate sub partu does not lead to a better neonatal outcome for boys in comparison to girls. Dunn et al. reported similar results where, in spite of a higher rate of interventions, lower Apgar scores, more reanimation procedures and a higher rate of respiratory distress were demonstrated for male babies [14]. Also in this context the question must be posed as to how reliable are the instruments used during birth to monitor the foetus and how valid is the interpretation of the so obtained data.

One limitation of this study is the lacking analysis of multifactorial events. This would have been suitable to more precisely describe indications, interventions and neonatal outcome in relation to foetal gender.

\section{Conclusion}

$\nabla$

According to these results male foetuses and babies exhibit a vulnerable constitution not only in the prepartal phase but also sub partu and post partum. On the basis of this finding, it is essential to generate further basic knowledge about the physiological and pathophysiological processes during pregnancy and birth in dependence on the gender of the foetus.

Then it would be possible to derive preventative, diagnostic and therapeutic measures according to the foetal gender and to apply them accordingly. This knowledge could contribute to an optimisation of obstetric management, especially with regard to a reduction in the rates of preterm births and preterm interventions.

\section{Conflict of Interest}

$\nabla$

None.

\section{References}

1 Ehrich JHH, Zivicnjak M, Hartmann H. Geschlechtsunterschiede im Kindesalter: Wachstum, Entwicklung und Krankheit. In: Rieder A, Lohff B, Hrsg. Gender Medizin. Geschlechtsspezifische Aspekte für die klinische Praxis. Wien: Springer; 2008: 73-88

2 Walker MG, Fitzgerald B, Keating $S$ et al. Sex-specific basis of severe placental dysfunction leading to extreme preterm delivery. Placenta 2012; 33: 568-571

3 Stanek J. Comparison of placental pathology in preterm, late-preterm, near-term, and term births. Am J Obstet Gynecol 2014; 210: 234.e1234.e6

4 Roberts DJ, Post MD. The placental in pre-eclampsia and intrauterine growth restriction. J Clin Pathol 2008; 61: 1254-1260

5 Sikkema JM, Franx A, Bruinse HW et al. Placental pathology in early onset pre-eclampsia and intra-uterine growth restriction in women with and without thrombophilia. Placenta 2002; 23: 337-342

6 Melamed N, Yogev Y, Glezerman M. Fetal gender and pregnancy outcome. J Matern Fetal Neonatal Med 2010; 23: 338-344

7 Di Renzo GC, Rosati A, Sarti RD et al. Does fetal sex affect pregnancy outcome? Gend Med 2007; 4: 19-30

8 Sheiner E, Levy A, Katz $M$ et al. Gender does matter in perinatal medicine. Fetal Diagn Ther 2004; 19: 366-369

9 Jaskolka D, Retnakara R, Zinman B et al. Sex of the baby and risk of gestational diabetes mellitus in the mother: a systematic review and meta-analysis. Diabetologia 2015; 58: 2469-2475

10 Aibar L, Puertas A, Valverde $M$ et al. Fetal sex and perinatal outcomes. J Perinat Med 2012; 40: 271-276

11 Khalil MM, Alzahra E. Fetal gender and pregnancy outcomes in Libya: a retrospective study. Libyan J Med 2013; DOI: 10.3402/ljm.v8i0.20008

12 Linder I, Melamed N, Kogan A et al. Gender and birth trauma in fullterm infants. J Matern Fetal Neonatal Med 2012; 25: 1603-1605

13 Brown ZA, Schalekamp-Timmermans S, Tiemeier HW et al. Fetal sex specific differences in human placentation: a prospective cohort study. Placenta 2014; 35: 359-364

14 Dunn L, Prior T, Greer R et al. Gender specific intrapartum and neonatal outcomes for term babies. Eur J Obstet Gynecol Reprod Biol 2015; 185: $19-22$

15 Frondas-Chauty A, Simon L, Branger B et al. Early growth and neurodevelopmental outcome in very preterm infants: impact of gender. Arch Dis Child Fetal Neonatal Ed 2014; 99: F366-F372

16 Peacock JL, Marston L, Marlow N et al. Neonatal and infant outcome in boys and girls born very prematurely. Pediatr Res 2012; 71: 305-310

17 Skiöld B, Alexandrou G, Padilla $N$ et al. Sex differences in outcome and associations with neonatal brain morphology in extremely preterm children. J Pediatr 2014; 154: 1012-1018

18 Moré A. Zur Geschlechtsspezifik bei (neuro)psychologischen und psychosomatischen Störungen aus der Sicht der pädiatrischen Psychologie. In: Rieder A, Lohff B, Hrsg. Gender Medizin. Geschlechtsspezifische Aspekte für die klinische Praxis. Wien: Springer; 2011: 89-106

19 Kautzky-Willer A. Editorial. In: Kautzky-Willer A, Hrsg. Gendermedizin: Prävention, Diagnose, Therapie. Wien: Böhlau; 2012: 7-16

20 Challis J, Newnham J, Petraglia $F$ et al. Fetal sex and preterm birth. Placenta 2013; 34: 95-99

21 Zeitlin J, Ancel PY, Larroque B et al. Fetal sex and indicated very preterm birth: results of the EPIPAGE study. Am J Obstet Gynecol 2004; 190: $1322-1325$ 